\title{
Communication
}

\section{Some Topological Invariants of the Möbius Ladder}

\author{
Shin Min Kang ${ }^{1}$, Mobeen Munir ${ }^{2}$, Abdul Rauf Nizami ${ }^{2}$, Zakia Shahzadi ${ }^{2}$ and Waqas Nazeer ${ }^{2, *}$ \\ 1 Department of Mathematics, Gyeongsang National University, Jinju 52828, Korea; smkang@gnu.ac.kr \\ 2 Division of Science and Technology, University of Education, Lahore, Pakistan; mmunir@ue.edu.pk \\ (M.M.); arnizami@ue.edu.pk (A.R.N.) zakiashahzadi@gmail.com (Z.S.) \\ * Correspondence: nazeer.waqas@ue.edu.pk; Tel.: +92-321-4707379
}

\begin{abstract}
In this article we compute many topological indices for the family of Möbius ladder. At first we give general closed form of M-polynomial of this family and recover many degree based topological indices out of it. We also compute Zagreb indices and Zagreb polynomials of this family.
\end{abstract}

Keywords: Möbius ladder; topological indices

\section{Introduction}

A graph invariant is a number, a polynomial, or a matrix which uniquely represents the whole graph [2]. Topological index is a graph invariant which characterizes the topology of the graph and remains invariant under graph automorphism. Degree based topological indices are of great importance and play a vital role in chemical graph theory see[6,17,18]. Wiener [15], working on boiling point of paraffin, introduced the idea of topological index. The Wiener index is originally the first and most studied topological index and is defined as the sum of distances between all pairs of vertices in $\mathrm{G}$, for more details see $[5,14,16]$. Zagreb indices, have been introduced 38 years ago by I. Gutman and N. Trinajstic [20]. First Zagreb index $M_{1}(G)$ is defined as sum of the squares of degrees of a graph $G$ and second Zagreb $M_{2}(G)$ is sum of the product of all degrees corresponding to each edge in $G$ see [20]. Second modified Zagreb index is defined by

$$
{ }^{m} M_{2}(G)=\Sigma_{u v \in E(G) \frac{1}{d(u) d(v)}}
$$

Where $d(u)$ and $d(v)$ are the degrees of vertices $u$ and $v$ respectively see [21]. General Randic index of $G$ is defined as sum of $(d(u) d(v))^{\alpha}$ over all edges $u v$ of $G$, where $d(u)$ denote the degree of vertex $u$ of $G$,

$$
R_{\alpha}(G)=\Sigma_{u v \in E(G)}(d(u) d(v))^{\alpha}
$$

Where $\alpha$ is an arbitrary real number see [22]. Symmetric division index is defined by

$$
\operatorname{SDD}(G)=\Sigma_{u v \in E(G)}\left(\frac{\min \left\{d_{u}, d_{v}\right\}}{\max \left\{d_{u}, d_{v}\right\}}+\frac{\min \left\{d_{u}, d_{v}\right\}}{\max \left\{d_{u}, d_{v}\right\}}\right)
$$

Where $d_{i}$ is the degree of vertex $i$ in Graph $G$. These indices can help to characterize the chemical and physical properties of molecules see [3,6,15,17-19,21-23]. Some standard degree based topological indices and the formulas how to compute them from $M$-polynomial. 


\begin{tabular}{|l|l|l|}
\hline Topological Index & $f(x, y)$ & Derivation from $M(G, x, y)$ \\
\hline First Zagreb & $x+y$ & $\left.\left(D_{x}+D_{y}\right)(M(G ; x, y))\right|_{x=y=1}$ \\
Second Zagreb & $x y$ & $\left.\left(D_{x} D_{y}\right)(M(G ; x, y))\right|_{x=y=1}$ \\
Second Modified Zagreb & $\frac{1}{x y}$ & $\left.\left(S_{x} D_{y}\right)(M(G ; x, y))\right|_{x=y=1}$ \\
General Randić $\alpha \in N$ & $(x y)^{\alpha}$ & $\left.\left(D_{x}^{\alpha} D_{y}^{\alpha}\right)(M(G ; x, y))\right|_{x=y=1}$ \\
General Randić $\alpha \in N$ & $\frac{1}{x y}$ & $\left.\left(S_{x}^{\alpha} S_{y}^{\alpha}\right)(M(G ; x, y))\right|_{x=y=1}$ \\
Symmetric Division Index & $\frac{x^{2}+y^{2}}{x y}$ & $\left.\left(D_{x} S_{y}+D_{y} S_{x}\right)(M(G ; x, y))\right|_{x=y=1}$ \\
\hline
\end{tabular}

where

$D_{x}(f(x, y))=x \frac{\partial f(x, y)}{\partial x}, D_{y}(f(x, y))=y \frac{\partial f(x, y)}{\partial y}, S_{x}(f(x, y))=\int_{0}^{x} \frac{f(t, y)}{t} d t, S_{y}(f(x, y))=\int_{0}^{y} \frac{f(x, t)}{t} d t$

The Möbius ladder $M_{n}$ which is a cubic circulant graph with an even number of vertices, formed from an $n$-cycle by adding edges (called "rungs") connecting opposite pair of vertices in the cycle. It is so-named because (with the exception of $M_{6}=K_{3,3}$ ) $M_{n}$ has exactly $\frac{n}{2}$ 4-cycles which link together by their shared edges to form a topological Möbius strip. Möbius ladders can also be viewed as a prism with one twisted edge. Two different views of Möbius ladders $M_{n}$ have been shown in Fig.1. Möbius ladders have many applications in Chemistry, Chemical Stereography, Electronics and Computer Science.

For our convenience, we view the Möbius ladder $M_{n}$ which is a cubic circulant graph with an even number of vertices, formed from an $n$-cycle by adding edges (called "rungs") connecting opposite pair of vertices in the cycle.

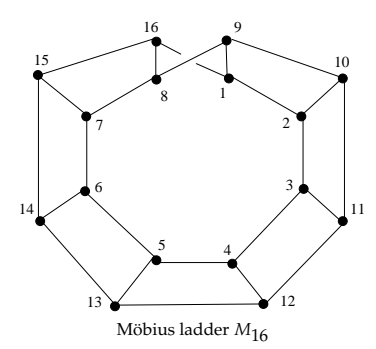

Definition 1. Let $G$ be a graph which is a simple molecular connected graph and $d_{v}\left(1 \leq d_{v} \leq n-1\right)$ be the degrees of vertices in $G$. We partition the set of vertex $V(G)$ and edge set $E(G)$ of $G$ as follows $(\forall i, j a n d k: \delta \leq i, j, k \leq \triangle): V_{k}=v \epsilon V(G) \mid d_{v}=k E_{i, j}=\left\{e=u v \epsilon E(G) \mid d_{u}=j a n d d_{v}=i\right\}$ where $\delta$ and $\triangle$ are the minimum and maximum of degree of $d_{v} \forall v \epsilon V(G)$ and $\delta=\operatorname{Min}\left\{d_{v} \mid v \epsilon V(G)\right\}$ and $\triangle=\operatorname{Max}\left\{d_{v} \mid v \in V(G)\right\}$, respectively. Now, let $G=(V, E)$ is a graph and let $m_{i j}$ be the number of degrees $e=u v$ of $G$ such that $\left\{d_{v}(G), d_{u}(G)\right\}=\{i, j\}$, then the $M$-polynomial of $G$ define as follows:

$$
M(G, x, y)=\Sigma_{\delta \leq i \leq j \triangle} m_{i j} x^{i} y^{j}
$$

where $d_{u}, d_{v}\left(1 \leq \delta \leq d_{u}, d_{v} \leq \triangle \leq|V(G)|-1\right)$ are the degrees of vertices $u, v \in V(G)$.

Ghorbani and Azimi defined two new versions of Zagreb indices of a graph G in 2012 [9]. The first multiple Zagreb index $P M_{1}(G)$, second multiple Zagreb index $P M_{2}(G)$ and these indices are defined as:

$$
\begin{aligned}
& P_{1}(G)=\prod_{u v \in E(G)}[\operatorname{deg}(u)+\operatorname{deg}(v)] \\
& P M_{2}(G)=\prod_{u v \in E(G)}[\operatorname{deg}(u) \times \operatorname{deg}(v)] .
\end{aligned}
$$


In 2013, Shirdel et al. [26] introduced a new degree based Zagreb index named hyper-Zagreb index as:

$$
H M(G)=\sum_{u v \in E(G)}[\operatorname{deg}(u)+\operatorname{deg}(v)]^{2}
$$

The properties of $P M_{1}(G), P M_{2}(G)$ indices for some chemical structures have been studied in $[4,7,9$, $11,22,25]$. The first Zagreb polynomial $M_{1}(G, x)$ and second Zagreb polynomial $M_{2}(G, x)$ are defined as:

$$
\begin{aligned}
& M_{1}(G, x)=\sum_{u v \in E\left(M_{n}\right)} x^{[\operatorname{deg}(u)+\operatorname{deg}(v)]}, \\
& M_{2}(G, x)=\sum_{u v \in E\left(M_{n}\right)} x^{[\operatorname{deg}(u) \times \operatorname{deg}(v)]} .
\end{aligned}
$$

The properties of $M 1(G, x), M 2(G, x)$ polynomials for some chemical structures have been studied in [10]. Nowadays there is an extensive research activity on $P M_{1}(G), P M_{2}(G), H M(G)$, indices, $M_{1}(G, x), M_{2}(G, x)$ polynomials and their variants, see also [7-9,12,13,20,26].

\section{Main Results}

Theorem 2. Let $M_{n}$ be Möbius ladder. Then the M-polynomial of $M_{n}$ is

$$
M\left(M_{n}, x, y\right)=3 n x^{3} y^{3}
$$

Proof. Let $M_{n}$ be Möbius ladder. From the structure of $M_{n}$ Möbius ladder we can see that only one partition $V_{3}=\left\{v \epsilon V\left(M_{n}\right) \mid d_{v}=3\right\}$. By definition of $M$-polynomial, we can see edge set of $M_{n}$ can be partition as follows: $E_{3,3}=\left\{e=u v \epsilon E\left(M_{n}\right) \mid d_{u}=d_{v}=3\right\} \rightarrow\left|E_{\{3,3\}}\right|=3 n$

In figure the size of $E_{\{3,3\}}$ is equal to $3 n$. Thus $M$-polynomial of $M_{n}$

$$
\begin{aligned}
M\left(M_{n}, x, y\right) & =\Sigma_{i \leq j} m_{i j}\left(M_{n}\right) x^{i} y^{j} \\
& =\Sigma_{3 \leq 3} m_{i j}\left(M_{n}\right) x^{3} y^{3} \\
& =\left|E_{\{3,3\}}\right| x^{3} y^{3} \\
& =3 n x^{3} y^{3}
\end{aligned}
$$

Now we derive topological indices which are directly derivable from $M$-polynomial.

Theorem 3. Let $M_{n}$ be Möbius ladder. Then

1. $M_{1}\left(M_{n}\right)=18 n$,

2. $M_{2}\left(M_{n}\right)=81 n^{2}$,

3. ${ }^{m} M_{2}\left(M_{n}\right)=n^{2}$,

4. $R_{\alpha}\left(M_{n}\right)=\left(81 n^{2}\right)^{\alpha}$,

5 .

$$
\operatorname{SDD}\left(M_{n}\right)=\left(n^{2}\right)^{\alpha}
$$

6. $\operatorname{SDD}\left(M_{n}\right)=18 n^{2}$.

Proof. Let $f(x, y)=3 n x^{3} y^{3}$, then $D_{x}(f(x, y))=9 n x^{2} y^{3}, D_{y}(f(x, y))=9 n x^{3} y^{2}, S_{x}(f(x, y))=$ $S_{y}(f(x, y))=n x^{3} y^{3},\left.D_{x}(f(x, y))\right|_{x=y=1}=\left.D_{y}(f(x, y))\right|_{x=y=1}=9 n$, and $\left.S_{x}(f(x, y))\right|_{x=y=1}=$ $\left.S_{y}(f(x, y))\right|_{x=y=1}=n$.

1. $\left.M_{1}\left(M_{n}\right):\left(D_{x}+D_{y}\right) f(x, y)\right)\left.\left(M\left(M_{n} ; x, y\right)\right)\right|_{x=y=1}=18 n$.

2. $\left.M_{2}\left(M_{n}\right):\left(D_{x} D_{y}\right) f(x, y)\right)\left.\left(M\left(M_{n} ; x, y\right)\right)\right|_{x=y=1}=81 n^{2}$.

3. $\left.{ }^{m} M_{2}\left(M_{n}\right):\left(S_{x} S_{y}\right) f(x, y)\right)\left.\left(M\left(M_{n} ; x, y\right)\right)\right|_{x=y=1}=n^{2}$. 
4. $\left.R_{\alpha}\left(M_{n}\right):\left(D_{x} D_{y}\right)^{\alpha} f(x, y)\right)\left.\left(M\left(M_{n} ; x, y\right)\right)\right|_{x=y=1}=\left(81 n^{2}\right)^{\alpha}$.

5. $\left.R_{\alpha}\left(M_{n}\right):\left(S_{x} S_{y}\right)^{\alpha} f(x, y)\right)\left.\left(M\left(M_{n} ; x, y\right)\right)\right|_{x=y=1}=\left(n^{2}\right)^{\alpha}$.

6. $\operatorname{SDD}\left(M_{n}\right):\left.\left(D_{x} S_{y}+D_{y} S_{x}\right)\left(M\left(M_{n} ; x, y\right)\right)\right|_{x=y=1}=18 n^{2}$.

Theorem 4. Let $M_{n}$ be Möbius ladder. Then

1. $P M_{1}\left(M_{n}\right)=6^{3 n}$,

2. $P M_{2}\left(M_{n}\right)=9^{3 n}$,

3. $H M\left(M_{n}\right)=36(3 n)$.

Proof. Let $M_{n}$ be Möbius ladder. Edge set of $M_{n}$ has one partition based on degree of vertices.The edge partition has $3 n$ edges $u v$ where $\operatorname{deg}(u)=\operatorname{deg}(v)=3$ it can easy to see that $\left|E_{1}\left(M_{n}\right)\right|=d_{33}$. Now using equations (1)-(3)we have,

1.

$$
\begin{aligned}
P M_{1}\left(M_{n}\right) & :=\prod_{u v \epsilon E\left(M_{n}\right)}[\operatorname{deg}(u)+\operatorname{deg}(v)] \\
& =\prod_{u v \epsilon E_{1}\left(M_{n}\right)}[\operatorname{deg}(u)+\operatorname{deg}(v)] \\
& =6^{\left|E_{1}\left(M_{n}\right)\right|} \\
& =6^{3 n}
\end{aligned}
$$

2.

$$
\begin{aligned}
& \mathrm{PM}_{2}\left(\mathrm{M}_{n}\right) \quad:=\quad \prod_{u v \in E\left(M_{n}\right)}[\operatorname{deg}(u) \times \operatorname{deg}(v)], \\
& =\quad \prod_{u v \in E_{1}\left(M_{n}\right)}[\operatorname{deg}(u) \times \operatorname{deg}(v)], \\
& =79^{\left|E_{1}\left(M_{n}\right)\right|}, \\
& =\quad 9^{3 n} \text {. }
\end{aligned}
$$

3.

$$
\begin{aligned}
\operatorname{HM}\left(M_{n}\right) & :=\sum_{u v \in E\left(M_{n}\right)}[\operatorname{deg}(u)+\operatorname{deg}(v)]^{2}, \\
& =\sum_{u v \epsilon E_{1}\left(M_{n}\right)}[\operatorname{deg}(u)+\operatorname{deg}(v)]^{2}, \\
& =36\left|E_{1}\left(M_{n}\right)\right|, \\
& =36(3 n) .
\end{aligned}
$$

Theorem 5. Let $M_{n}$ be Möbius ladder. Then

1. $M_{1}\left(M_{n}, x\right)=3 n x^{6}$

2. $M_{2}\left(M_{n}, x\right)=3 n x^{9}$.

Proof. Let $M_{n}$ be Möbius ladder. Edge set of $M_{n}$ has one partition based on degree of vertices. The edge partition has $3 n$ edges $u v$ where $\operatorname{deg}(u)=\operatorname{deg}(v)=3$ it can easy to see that $\left|E_{1}\left(M_{n}\right)\right|=d_{33}$. Now using equations (4)-(5)we have, 
1.

$$
\begin{aligned}
M_{1}\left(M_{n}\right. & :=\sum_{u v \in E\left(M_{n}\right)} x^{[\operatorname{deg}(u)+\operatorname{deg}(v)]}, \\
& =\sum_{u v \in E_{1}\left(M_{n}\right)} x^{[\operatorname{deg}(u)+\operatorname{deg}(v)]}, \\
& =\left|E_{1}\left(M_{n}\right)\right| x^{6}, \\
& =3 n x^{6} .
\end{aligned}
$$

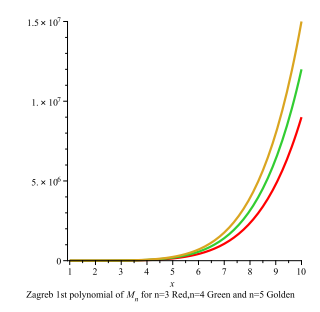

2.

$$
\begin{aligned}
P_{2}\left(M_{n}\right) & :=\sum_{u v \in E\left(M_{n}\right)} x^{[\operatorname{deg}(u) \times \operatorname{deg}(v)]}, \\
& =\sum_{u v \in E_{1}\left(M_{n}\right)} x^{[\operatorname{deg}(u) \times \operatorname{deg}(v)]}, \\
& =\left|E_{1}\left(M_{n}\right)\right| x^{9}, \\
& =3 n x^{9} .
\end{aligned}
$$

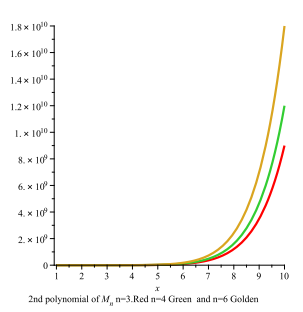

Author Contributions: All authors contributed equally to the writing of this paper. All authors read and approved the final manuscript.

Conflicts of Interest: "The authors declare no conflict of interest."

\section{References}

1. M. Mobeen, A. R. Nizami, H. Saeed, Z. Iqbal, Metric dimension of Mobious Ladder, Article In Press, Ars Cominatorica.

2. D. B. West,An introduction of Graph Theory, Prentice-Hall (1996).

3. G. Rucker and C. Rucker,On topological indices, boiling points, and cycloalkanes, J. Chem. Inf. Comput.Sci.39,788(1991).

4. B. Borovicanin, On the extremal Zagreb indices of trees with given number of segments or given number of branching vertices,MATCH Commun. Math. Comput. Chem. 74 (1) (2015) 57-79.

5. A. A. Dobrynin, R. Entringer, I. Gutman, Wiener index of trees: theory and applications, Acta Appl. Math. 66 (2001) 211-249.

6. W. Du, X. Li, Y. Shi, Algorithms and extremal problem on Wiener polarity index, MATCH Commun. Math. Comput. Chem. 62 (1) (2009) 235=244. 
7. M. Eliasi, A. Iranmanesh, I. Gutman, Multiplicative version of first Zagreb index, MATCH Commun. Math. Comput. Chem. 68 (2012) 217-230.

8. B. Furtula, I. Gutman, M. Dehmer, On structure-sensitivity of degree-based topological indices, Appl. Math. Comput. 219 (2013) 8973-8978.

9. M. Ghorbani, N. Azimi, Note on multiple Zagreb indices, Iran. J. Math. Chem. 3 (2) (2012) 137-143.

10. I. Gutman, K. C. Das, Some Properties of the Second Zagreb Index, MATCH Commun. Math. Comput. Chem. 50 (2004) 103-112.

11. I. Gutman, B. Furtula, Z. K. Vukicevic, G. Popivoda, On Zagreb Indices and Coindices, MATCH Commun. Math. Comput. Chem. 74 (1) (2015) 5-16.

12. I. Gutman, Degree-based topological indices, Croat. Chem. Acta. 86 (2013) 351.361.

13. S. Hayat, M. Imran, Computation of topological indices of certain networks, Appl. Math. Comput. 240 (2014) 213.228.

14. I. Gutman, O.E. Polansky, Mathematical Concepts in Organic Chemistry, Springer-Verlag, New York, 1986.

15. H. Wiener, Structural determination of paraffin boiling points, J. Am. Chem. Soc. 69 (1947) 17-20.

16. K. Xu, M. Liu, K.C. Das, I. Gutman, B. Furtula, A survey on graphs extremal with respect to distance-based topological indices, MATCH Commun. Math.Comput. Chem. 71 (2014) 461-508.

17. J. Ma, Y. Shi, J. Yue, The wiener polarity index of graph products, Ars Combin. 116 (2014) 235-244.

18. J. Ma, Y. Shi, Z. Wang, J. Yue, On wiener polarity index of bicyclic networks, Sci. Rep. 6 (2016) 19066, doi:10.1038/srep19066.

19. M. K. Shaddiqi., M.Imran, A. A. Baig, On Zagreb indices, zagreb polynomials of some nanostar dendrimers Appl. Math and Comp. 280(2016)132-136.

20. I. Gutman, N. Trinajstic, Graph theory and molecular orbitals total $\phi$-electron energy of alternant hydrocarbons, Chem. Phys. Lett. 17 (1972) 535.538

21. A. Vasilyev Upper and Lower bounds of symmetric division deg index, Iranian Journal of Math. Chemistry, Vol.5, No.2, November 2014, 19-98.

22. X. Li and Y. Shi, A Survey on the Randiac Index, MATCH Commun. Math. Comput. Chem. 59(2008) 127-156.28

23. J. Hao, Theorems about Zagreb Indices and Modified Zagreb Indices, MATCH Commun. Math. Comput. Chem. 65 (2011) 659-670.

24. M. Munir, S. Rafique, A. R. Nizami, Z. Shahzadi, M. I. Khan M-polynomial and degree-based topological indices of Buckytubes, Article in press J. COMPUT. THEOR. NANOS.

25. Y. Shi, Note on two generalizations of the Randic index, Appl. Math. Comput. 265 (2015) 1019-1025.

26. G. H. Shirdel, H. R. Pour, A. M. Sayadi, The Hyper-Zagreb index of graph operations, Iran. J. Math. Chem. 4 (2) (2013) 213-220.

27. S. Khuller, B. Raghavachari, A. Rosenfeld Location in graphs, Technical Report CS-TR-3326, University of Maryland at Colleg Park, 1994.

(C) 2016 by the authors; licensee Preprints, Basel, Switzerland. This article is an open access article distributed under the terms and conditions of the Creative Commons Attribution (CC-BY) license (http://creativecommons.org/licenses/by/4.0/). 